\title{
Estimulando o pensamento computacional e o raciocínio lógico no ensino fundamental por meio da OBI e computação desplugada
}

\author{
Jessica Silva de Souza, Alba Sandyra Bezerra Lopes \\ Campus Natal-Zona Norte - Instituto Federal do Rio Grande do Norte (IFRN) \\ Natal - Rio Grande do Norte - Brasil \\ jessica.silvadescolar.ifrn.edu.br, alba.lopesdifrn.edu.br
}

\begin{abstract}
The logical thinking development is an essential process to assist in problem solving in several areas, including computing. The Brazilian Olympiad of Informatics (OBI) is a knowledge olympiad supported by Brazilian Society of Computing that emerges as an opportunity to encourage students to become interested in and deepen in the area of computing and technology. This Olympiad is in its 20th edition. In this context, this paper present an activity developed by students of PIBID in a public elementary school intending to contribute with the development of logical and computational thinking through the unplugged computation associated with the activities proposed by OBI.

Resumo. O desenvolvimento do raciocínio lógico é um processo fundamental para auxiliar na resolução de problemas em diversas áreas, inclusive na computação. A Olimpíada Brasileira de Informática (OBI) é uma olimpíada do conhecimento que promove o desenvolvimento dessa competência através da resolução de desafios e visa estimular o interesse dos alunos para a área da computação. Nesse contexto, apresenta uma ação realizada por meio do PIBID em uma escola pública de um município do estado visando auxiliar no desenvolvimento do raciocínio lógico e pensamento computacional por meio da computação desplugada associada aos desafios propostas pela OBI.
\end{abstract}

\section{Introdução}

O pensar computacionalmente não está restrito apenas à área da computação, mas apresenta-se como uma competência que, de acordo com Cavalcante et al (2016), consiste no conjunto de habilidades e atitudes vinculadas na realização de uma ação, cujo principal objetivo é o da resolução de problemas, sendo assim relevante para todas as pessoas. No contexto educacional brasileiro, o pensamento computacional foi inserido na nova base nacional comum curricular como uma das competências atreladas à área de Matemática e suas Tecnologias, assim como o raciocínio lógico [Brasil, 2017].

Dentre as inciativas nacionais para estímulo ao desenvolvimento do raciocínio lógico e do pensamento computacional está a Olimpíada Brasileira de Informática. De acordo com [Martins, 2011], a OBI aproxima a universidade dos ensinos médio e fundamental e com isso promove a introdução de conceitos de lógica e programação de computadores nesses níveis.

Também no contexto do estímulo ao pensamento computacional, a utilização da metodologia de computação desplugada para adaptação no ensino de conteúdo tem sido relatada como uma metodologia com bastante aceitação por parte dos alunos, por ser uma 
VII Congresso Brasileiro de Informática na Educação (CBIE 2018)

Anais do XXIX Simpósio Brasileiro de Informática na Educação (SBIE 2018)

estratégia lúdica se caracterizando como um método de ensino de computação sem o uso do computador [Bell et al., 2011]. Assim, mesmo em escolas que não dispõe de equipamentos, o pensamento computacional pode ser estimulado através do uso dessa técnica.

Nesse contexto, o trabalho relatado aqui apresenta uma ação realizada por alunos do PIBID de um curso de Licenciatura em Informática que teve como objetivo estimular o raciocínio lógico e pensamento computacional em alunos do ensino fundamental de uma escola pública do estado que não dispunha de laboratório de informática, através do uso de dinâmicas de computação desplugada que foram elaboradas tendo como base questões extraídas de provas da OBI. Essas dinâmicas foram realizadas com alunos do $5^{\circ}$ ano do ensino fundamental.

\section{Metodologia}

A OBI é dividida em três modalidades, de acordo com o site oficial da olimpíada ${ }^{1}$ : iniciação, programação e universitária. A modalidade de iniciação é a modalidade que abrange o ensino fundamental, é subdividida em nível 1, para alunos que cursem até o sétimo ano do ensino fundamental, e nível 2 para aqueles que cursam até o nono ano do ensino fundamental. Nessa modalidade, são aplicadas provas teóricas compostas por questões de múltipla escolha que abordam conteúdos de raciocínio lógico.

Dessa forma, os alunos do PIBID buscaram provas passadas da OBI da modalidade de iniciação e extraíram questões que pudessem trabalhar os conceitos do raciocínio lógico e pensamento computacional por meio de dinâmicas. As dinâmicas buscaram abordar as questões mais frequentes nas provas da OBI, considerando o quadro a seguir, extraído da pesquisa realizada por (Martins, 2011)

\begin{tabular}{|c|c|c|}
\hline \multirow{2}{*}{ Regra } & \multicolumn{2}{|c|}{ Tipo de Questão } \\
\hline & Ordenação & Agrupamento \\
\hline Posicionamento & Frequente & \\
\hline Atribuição & & Frequente \\
\hline Sequenciamento & Muito Frequente & \\
\hline Combinação & Frequente & Pouco Frequente \\
\hline Condicional & Ocasional & Muito Frequente \\
\hline
\end{tabular}

Tabela 1. Frequência de abordagem do tipo de questões na prova da OBI Fonte: (Martins, 2011- pg 27)

Ao todo, foram elaboradas 5 dinâmicas, baseadas no caderno da OBI, na modalidade de Iniciação Nível 1 - Fase 1 do ano de $2015^{2}$. Essas dinâmicas foram trabalhadas em diferentes dias durante a atuação dos alunos no PIBID.

Dinâmica 1 - Reunião na Mesa Redonda: (baseada na questão 01): essa dinâmica teve como objetivo trabalhar os princípios da resolução de questões do tipo posicionamento. A questão na qual essa dinâmica foi baseada tinha como enunciado a disposição de cinco amigos em uma mesa redonda (Alberto, Beto, Cláudio, Dino e Eurico), considerando restrições de disposição desses amigos na mesa. A questão visava

\footnotetext{
${ }^{1}$ http://olimpiada.ic.unicamp.br

${ }^{2}$ https://olimpiada.ic.unicamp.br/static/extras/obi2015/provas/ProvaOBI2015_fli1.pdf
} 
responder quem eram os amigos sentados ao lado de Eurico. Para trabalhar esses conceitos, os alunos foram divididos em grupos de 5. Em seguida, foram distribuídas tampas de garrafa pet com as letras de A a E escritas em cada tampa, cada uma tampa representando um amigo. Cada estudante do grupo representou um dos amigos da questão. Os alunos foram estimulados a considerar as restrições e chegar à solução da questão. Também foram apresentadas outras restrições diferentes das propostas na questão de forma a trabalhar ainda mais os conceitos.

Dinâmica 2 - Caminho do Robô (baseada na questão 03): essa dinâmica teve como objetivo trabalhar questões do tipo ordenação (sequenciamento). A questão base tinha como enunciado a movimentação de um robô de acordo com as posições representadas por um conjunto de setas numeradas. Dado um determinado caminho, a questão pedia para dizer a sequência de números utilizada para traçar o caminho feito pelo robô. Para a aplicação da dinâmica, as direções possíveis e suas numerações foram transcritas no quadro. Além disso, foi utilizado fita crepe para traçar no chão alguns caminhos feitos pelo robô. Os alunos tinham que escrever em uma folha os números equivalentes a direção que usaram para concluir o trajeto. A atividade foi sendo desenvolvida aumentando o nível de complexidade: inicialmente foi ilustrado com fita crepe um pequeno número de movimentos feitos pelo robô, e a cada etapa, era incrementada essa quantidade de movimentos e feito o devido ajuste do caminho no chão; bem como variar os tipos de caminho.

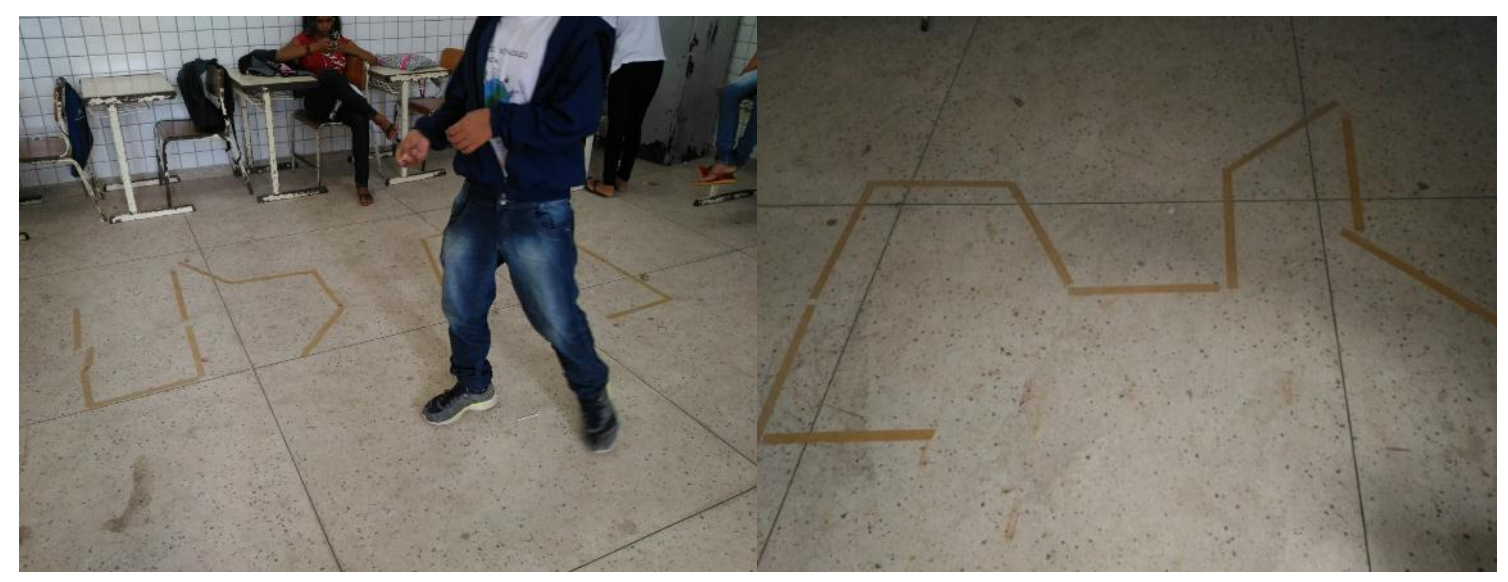

(a)

(b)

Figura 1. Aplicação da dinâmica 2 (Caminho do Robô)

Dinâmica 3 - Agrupamento de Mesa (baseada na questão 04): essa dinâmica foi elaborada visando trabalhar os princípios de resolução de questões do tipo agrupamento. Para tanto, foi reproduzido o enunciado de uma questão que envolvia determinar a quantidade de estudantes que poderiam sentar em um conjunto de mesas agrupadas. Assim, buscou-se reproduzir a situação utilizando as carteiras e cadeiras da sala de aula dos alunos e foi pedido que os alunos sentassem ocupando as cadeiras. A medida que novos alunos eram convidados a sentar, era preciso acrescentar uma carteira. Assim, deveriam ser retiradas cadeiras que ficavam no lugar onde as carteiras ficariam agrupadas. Com a aplicação dessa atividade, os alunos chegaram à conclusão que a cada junção de mesas, era necessário tirar um par de cadeiras.

Dinâmica 4 - Países vizinhos (baseada na questão 08): essa dinâmica teve como objetivo trabalhar os conceitos de grafos e também de questões do tipo agrupamento 
VII Congresso Brasileiro de Informática na Educação (CBIE 2018)

Anais do XXIX Simpósio Brasileiro de Informática na Educação (SBIE 2018)

(condicional, combinação e posicionamento). A questão era relacionada a um conjunto de mapas e deveria ser identificada a relação de fronteira entre os países do mapa, sendo representada essa relação por meio de grafos. Os alunos foram divididos em grupos de quatro a cinco alunos. Cada aluno foi definido com o nome de um país. De pé, eles representaram os países e se um fossem vizinhos um do outro, colocavam a mão no ombro do colega, para representar essa ligação. Foi explicado aos alunos que cada um deles representava um vértice e seus braços estendidos representavam as arestas. Em seguida, eles foram estimulados a, dado uma determinada configuração de mapa, representar humanamente o grafo associado àquele mapa.

Dinâmica 5 - Show de talentos (baseada nas questões de 09 a 14): essa dinâmica teve como objetivo trabalhar os conceitos associados às questões de ordenação (combinação, posicionamento). O enunciado geral trabalhado nesse conjunto de questões consistia de um show de talentos que apresentava um conjunto de regras e condições para a ordem de apresentação dos participantes. Para a aplicação da dinâmica, os alunos foram identificados com as letras de A à $\mathrm{G}$, onde cada uma das letras representava um participante do show de talentos, e à eles foram atribuídos os papéis descritos no cenário das questões. Cada um dos alunos foi orientado a anotar as regras que estavam relacionadas ao participante do show de talentos que ele representava, para que, dessa forma, não esquecessem as regras, e pudessem discutir a solução. Por fim, eles foram motivados a decidir entre si, seguindo as regras, a ordem de apresentação e apresentar a resposta para a turma. Após cada solução, eram apresentadas novas regras e os alunos novamente deveriam definir entre si apresentado a nova questão com condições diferentes.

\section{Avaliação da atividade realizada}

O uso de atividades em grupos com dinâmicas propiciou maior envolvimento dos alunos. Os alunos se apresentaram curiosos e dispostos a participar das atividades. Como em qualquer turma do quinto ano, alguns alunos eram mais dispersos que outros e também foram identificadas dificuldades de leitura e compreensão dos enunciados.

Para avaliar a assimilação do conteúdo pelos alunos, foram aplicadas duas avaliações: uma anterior à aplicação das dinâmicas (Avaliação 1) e outra posterior (Avaliação 2). Essas avaliações foram compostas por conjuntos de 10 questões distintos, levando em considerando os diferentes tipos de questões trabalhadas na OBI. Para a elaboração dessas avaliações também foram extraídas questões de anos anteriores das provas da OBI.

Na aplicação da Avaliação 1, os alunos tiveram o primeiro contato com provas do formato da Olimpíada, e não tinham recebido nenhuma orientação prévia. Devido a isso, como é possível observar na Figura 2, a grande maioria obteve um rendimento consideravelmente baixo. A maior quantidade de acertos obtida foi de 5 questões, pelos alunos 7 e 14, enquanto a média geral da turma foi de 2,8 acertos.

Considerando a avaliação feita após a aplicação das dinâmicas (Avaliação 2) houve um crescimento do rendimento de todos os alunos da turma, como pode ser observado na Figura 2, havendo alunos que acertaram até 8 das 10 questões. Nesse cenário, a média da turma foi elevada para 5,5. Questionados sobre a contribuição das dinâmicas na resolução dos problemas, os alunos relataram que após realizarem as dinâmicas, eles buscavam fazer uma associação sobre a atividade prática das dinâmicas 
VII Congresso Brasileiro de Informática na Educação (CBIE 2018)

Anais do XXIX Simpósio Brasileiro de Informática na Educação (SBIE 2018)

que tinham realizado com o enunciado da questão, contribuindo para a compreensão do enunciado.

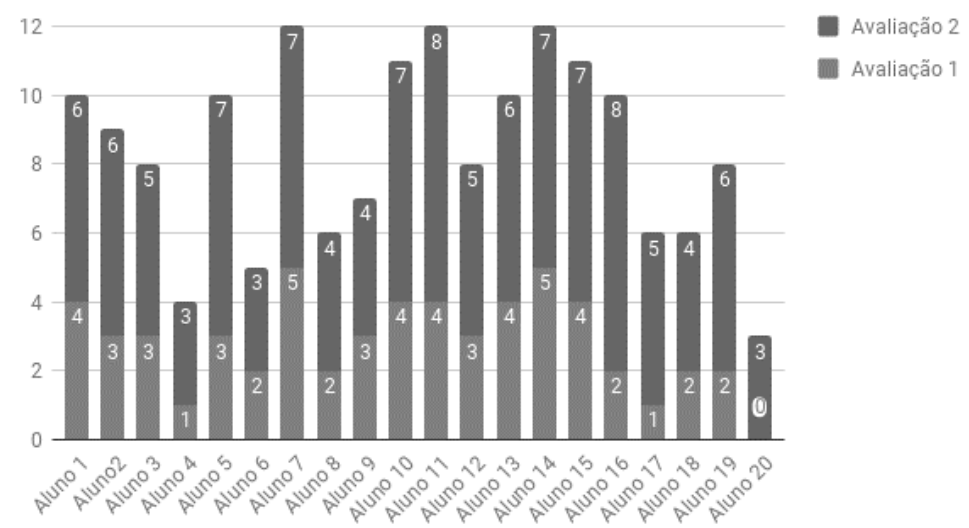

Figura 2. Avaliação da assimilação do conteúdo trabalhado

\section{Considerações finais}

Esse trabalho apresentou um relato de experiência de uma ação do PIBID de um curso superior de Licenciatura em Informática em uma escola do pública de um município do estado com alunos do $5^{\circ}$ ano do ensino fundamental. Através do uso de dinâmicas para o desenvolvimento do raciocínio lógico e pensamento computacional, os alunos foram estimulados a compreender os conceitos abordados nas questões da OBI. Em avaliação da ação realizada, foi constatado um aumento de rendimento em todos os alunos que participaram das atividades envolvendo as dinâmicas e que relataram que as dinâmicas contribuíram para a compreensão do enunciado das questões. Como trabalhos futuros, pretende-se inscrever a escola na OBI e propiciar a participação dos alunos na competição. Também é pretendido expandir a divulgação da olimpíada para outras escolas da região e reproduzir a experiência do uso das dinâmicas na preparação de novos conjuntos de alunos nesse tipo de competição.

\section{Referências}

Bell, Timothy C., Ian H. Witten, and Mike Fellows. Computer Science Unplugged: Offline activities and games for all ages. Computer Science Unplugged, 1998.

BRASIL. Ministério da Educação. Secretaria da Educação Básica. Base nacional comum curricular. Brasília, DF, 2017. Disponível em: < http://basenacionalcomum. mec.gov.br >. Acesso em: abr.2018

Cavalvante, Ahemenson Fernandes. COSTA, Cavalcante, Leonardo dos Santos. ARAÚJO, Ana Liz Souto Oliveira de. Um Estudo de Caso Sobre Competências do Pensamento Computacional Estimuladas na Programação em Blocos no Code.Org. In: Anais dos Workshops do V Congresso Brasileiro de Informática na Educação. Uberlândia/MG. 2016.

Martins, W. S. Jogos de Lógica: divirta-se e prepare-se para a Olimpíada Brasileira de Informática. Goiânia: Vieira, 2011. 158 p. 